\title{
MACEIÓ NOS JORNAIS: TRANSFORMAÇÕES URBANAS DO RIACHO MACEIÓ (1947-1949)
}

Maceió In The Papers: Urban Transformations of The Creek Maceió (1947-1949)

\author{
Carlina Rocha de Almeida Barros \\ Centro Universitário CESMAC \\ carlinarocha@hotmail.com
}

\section{Caroline Gonçalves dos Santos}

Centro Universitário CESMAC

santoscarolineg@yahoo.com.br

\section{Roberta Félix Maia}

Centro Universitário CESMAC

robertamaiaa@outlook.com

\section{Sibéria Freitas de Carvalho}

Centro Universitário CESMAC

siberiafreitas@hotmail.com

\section{Resumo}

Na cidade de Maceió ( $A L$ ) o riacho Maceió teve presença marcante no início da ocupação urbana, caracterizando-se como elemento de importância paisagística e referencial do lugar. Com a crescente necessidade de expansão da cidade uma drástica mudança ocorreu no final da década de 1940, quando se iniciaram as obras de retificação do riacho afetando sua simbologia e apropriação, e alterando sua relação com o meio urbano. Propõe-se uma reflexão sobre um recorte do espaço urbano de Maceió a partir de transformações que alteraram significativamente o curso do riacho e que foram noticiadas pelos jornais. Para isso foram levantadas reportagens acerca do riacho de 1947 a 1949 no intuito de colaborar no entendimento da mudança simbólica desse elemento natural e de suas relações com a sociedade.

\section{Palavras-chave}

Paisagem, Imprensa, Intervenção Urbana 


\begin{abstract}
In the city of Maceió ( $A L)$, the Maceió creek had strong presence in the beginning of urban occupation, characterized as an element of landscape importance and referential of place. With the growing need for expansion of the city a drastic change has occurred at the end of the Decade of 1940, when started the works of straightening of the creek affecting your symbology and appropriation, and changing its relationship with the urban environment. This article proposes a reflection on a cutout of the urban space of Maceió from transformations that significantly altered the course of the creek and were reported by newspapers. Therefore were analyzednewspapers reports about the creek of 1947 to 1949 with the aim of collaborating in the understanding of the symbolic change of this natural element and its relationship with society.
\end{abstract}

\title{
Keywords
}

Landscape, Press, Urban Intervention

\section{Relações entre espaço e sociedade}

As relações entre o homem e o meio físico natural sempre se deram através da técnica, que com o passar do tempo foi evoluindo em detrimento de um maior domínio sobre a natureza. As transformações que foram operadas refletem não apenas mudanças materiais como também socioculturais, que geram aquilo que Santos (2006) chama de espaço, resultado de uma complexa rede de relações entre sociedade e natureza influenciada pelo desenvolvimento da técnica. Esse fato possibilitou um domínio cada vez maior do meio natural pelo homem, especialmente com a evolução das sociedades modernas, que trouxeram consigo novas relações de produção e trabalho e a criação de ambientes urbanos mais adensados e carentes de salubridade.

A pressão cada vez maior do meio urbano sobre os elementos naturais, estes cada vez mais incorporados, influenciou na forma como esses elementos foram (e continuam sendo) apropriados e percebidos pela sociedade em momentos históricos e segundo interesses diversos. 
[...] Desse modo, o conhecimento dos sistemas técnicos sucessivos é essencial para o entendimento das diversas formas históricas de estruturação, funcionamento e articulação dos territórios, desde os albores da história até a época atual. Cada período é portador de um sentido, partilhado pelo espaço e pela sociedade, representativo da forma como a história realiza as promessas da técnica. (SANTOS, 2006, p. 62)

Com a transformação do meio físico natural através do desenvolvimento da técnica, o meio urbano pôde se expandir e supostamente dominar os elementos naturais presentes em seus perímetros cada vez mais extensos, de forma muitas vezes drástica e com sérias consequências. "O meio urbano é cada vez mais um meio artificial, fabricado com restos da natureza primitiva, crescentemente encobertos pelas obras do homem" (SANTOS, 2012, p. 46).

No Brasil, assim como em outros países do mundo, como resposta a essas novas demandas urbanas, foram desencadeadas profundas alterações nos elementos físicos naturais presentes nas cidades, sendo os rios um dos que sofreram maior influência da técnica a serviço do homem. Grandes, médios e pequenos corpos d'água estão presentes em localidades urbanas diversas, configurando-se como essenciais na formação e evolução desses espaços. Inicialmente eram utilizados como meio de circulação de pessoas e mercadorias, além de se apresentarem como importantes elementos de onde muitos retiravam o seu sustento e lazer.

Especialmente ao longo dos séculos $\mathrm{XIX}$ e $\mathrm{XX}$, momentos cruciais no desenvolvimento da técnica pelo homem, os rios urbanos foram sendo alterados, resultado de interesses higienistas e também de cunho econômico. Diante dessas novas relações entre sociedade e espaço ocorrem transformações não apenas materiais, de retificação ou canalização dessas águas, mas também de sentido e apropriação desses elementos naturais pela sociedade.

As transformações decorrentes da ação do homem sobre esse elemento natural e suas margens, num processo de construção social ao longo da história, resultaram nas paisagens atuais repletas de diversas camadas de significados. (ANTUNES, 2006, p. 121)

A ação do homem sobre os cursos d'água urbanos desencadeou uma série de intervenções muitas vezes desastrosas para o meio ambiente e que influenciaram de forma decisiva a maneira como esses elementos foram sendo incorporados ao meio urbano, expressão das relações sociais. As consequências dessa ação implicam em transformações no meio urbano que são registradas pela mídia no decorrer do tempo, 
apresentando o discurso realizado na época e os fatos históricos que marcaram a cidade.

\section{A mídia como instrumento de persuasão}

A complexidade das ações humanas sobre o espaço acarreta num distanciamento cada vez mais evidente do espaço natural, tornando a paisagem um conjunto heterogêneo de formas naturais e artificiais, cada vez mais significativo. Esse processo histórico e seus aspectos socioculturais, econômicos e políticos vem sendo registrado pela mídia ao longo do tempo.

Desde o século $X X$, os meios de comunicação de massa ${ }^{1}$ são elementos fundamentais na organização da sociedade, através deles a informação é transmitida ou comunicada. Essas informações parecem ser proporcionadas diretamente a cada indivíduo, havendo certa padronização da forma e do controle do que está sendo transmitido.

Apesar de sua lógica obedecer a uma homogeneização da sociedade, deve-se levar em consideração que os meios de comunicação se dirigem a pessoas que estão expostas a dificuldades sociais e às tensões da vida cotidiana.

É certo que os meios de comunicação também trabalham sobre essas esferas e procuram dar-lhes explicações e soluções. Mas por mais homogêneo que fosse seu conteúdo, não parece que sejam capazes de produzir uma massificação tão eficaz a ponto de substituir totalmente a percepção que seus consumidores têm de suas relações sociais e de suas vidas. (SANTOS, 2006, p. 70)

A existência desses instrumentos traz consequências objetivas nos contextos sociais, no pensar e agir dos diversos grupos de pessoas, influenciando e ditando comportamentos. Apesar disso, é notório que mesmo com a intenção de homogeneizar as massas, estas continuam fortemente diferenciadas em seu interior no que se refere aos diversos campos da nossa sociedade, que formam desigualdades e hierarquias sociais.

Chauí (2006) focaliza a questão do exercício do poder pelos meios de comunicação de massa a partir de dois aspectos principais: o econômico e o ideológico. O primeiro refere-se aos meios de comunicação como empresas privadas, ou seja, uma indústria cultural conduzida pelos interesses do capital, permitindo sua

\footnotetext{
${ }^{1}$ De acordo com Chauí (2006) a expressão comunicação de massa foi criada para se referir aos objetos tecnológicos que podem transmitir uma mesma mensagem para uma grande quantidade de pessoas.
} 
reprodução automática. Do ponto de vista ideológico ${ }^{2}$, para homogeneizar a sociedade com um único pensamento torna-se necessário veicular a informação lhe conferindo uma generalidade social, devendo existir uma reciprocidade verdadeira nas relações sociais.

A informação é produzida dessa forma pelo comunicador, que explicita e interpreta as notícias, cria uma espécie de síntese sobre os principais acontecimentos de uma cidade, sejam econômicos, sociais, políticos, culturais, religiosos ou esportivos. Esse domínio de informações de todas as esferas da sociedade possibilita aos meios de comunicação procederem de maneira a persuadir ou influenciar diversas camadas da população. No entanto, percebe-se uma mudança no papel da comunicação com relação à abordagem que deve ser dada às suas notícias:

Ideologicamente, portanto, o poder da comunicação de massa não é igual ou semelhante ao da antiga ideologia burguesa, que realizava uma inculcação de valores e ideias. Dizendo-nos o que devemos pensar,sentir, falar e fazer, afirma que nada sabemos e seu poder se realiza como intimidação social e cultural. (CHAUÍ, 2006, p. 77)

A informação veiculada serve de suporte para a produção, reprodução e divulgação dos bens do capital, sem, contudo, intimidar o leitor, fazendo isto de forma sutil, por meio do aparato tecnológico. Essa capacidade é considerada a supremacia do poder da mídia, onde se utiliza da ausência de referência temporal e espacial. A temporal trata dos argumentos que são relatados como se não tivessem causas passadas e nem efeitos no futuro; já a espacial, das diferenças geográficas e territoriais que são ignoradas.

Com isso, percebe-se que não se deve apenas estudar as mensagens contidas nesses meios de comunicação, acreditando que a cultura da sociedade se resuma apenas ao que esses meios alegam. Pois, "as mensagens da indústria cultural, com propósitos de homogeneização e controle das populações, podem ser um projeto dos interesses dominantes da sociedade, mas não são a cultura dessa sociedade" (SANTOS, 2006, p. 71).

Apesar dessa discussão, os acontecimentos dados pelo movimento da sociedade recorrem a um uso diversificado do trabalho e da informação. Ou seja, as notícias não deixam de apresentar aspectos importantes sobre a memória de uma cidade, relatando fatos históricos e como acontecia o cotidiano de certa época. Além

\footnotetext{
${ }^{2}$ Neste caso, a ideologia se apresenta desprovida de localização, tendo um discurso anônimo e impessoal.
} 
do que, registram as transformações ocorridas numa sociedade através das atividades produzidas pelos homens, que configuram esse todo complexo da paisagem, não podendo dessa forma separar a paisagem das condições políticas, econômicas e socioculturais.

Nesse sentido, as paisagens urbanas sofrem grande interferência a todo instante e para compreendê-las é preciso explicar sua gênese temporal. Essa compreensão deve estar associada à dinâmica da própria sociedade, de seu conjunto de técnicas, de sua divisão social do trabalho. Isso permitirá a construção da paisagem em suas várias etapas, que vai se somando e adquirindo novos significados, especialmente a partir das intervenções diretas do ser humano no território natural que em muitos casos se dá de forma drástica e negativa.

A partir desse entendimento, este artigo pretende refletir sobre a intervenção urbana ocorrida no riacho Maceió em meados do século XX com base nas notícias veiculadas no Jornal de Alagoas, referentes ao período de 1947 a 1949. Ao todo, foram consultadas 21 edições, verificando os discursos e argumentos que trataram da importância da obra para o desenvolvimento urbano da capital alagoana, bem como osimpactos trazidos pela retificação do riacho.

O Jornal de Alagoas foi fundado em 31 de maio de 1908 por Luiz Magalhães da Silveira, circulou durante 85 anos, paralisando suas atividades em 1993. Entre os jornais no formato diário, era o mais antigo da cidade de Maceió (MARROQUIM, 1922), passando a integrar o Diário dos Associados em 1936.

De modo que foi escolhido por ser um importante veículo de informação e comunicação em circulação durante o recorte temporal adotado. Por sua vez, o recorte se refere ao período do ápice das transformações pelas quais o riacho Maceió vinha passando, quando da definição e execução da alteração do seu curso, modificando bruscamente a sua foz.

\section{O riacho Maceió na evolução urbana de Maceió/Alagoas}

O Estado de Alagoas, localizado no Nordeste brasileiro, traz em sua toponímia uma alusão às suas águas, especialmente as doces que inicialmente foram primordiais para o desenvolvimento e transporte local, transformando aos poucos as paisagens fluviais em paisagens urbanas. Não à toa sua gente é descrita por Lindoso (2005) como um povo "anfíbio" que através das águas desenvolveu seu território. 
A cidade de Maceió ${ }^{3}$, atual capital do Estado, tem como limites a Leste o oceano Atlântico e a Oeste a lagoa Mundaú, e desde o seu surgimento estabeleceu uma relação intrínseca com suas águas, especialmente a partir das ligações marítima e fluvial (Imagem 1). Além desses dois grandes corpos d'água que delimitam sua geografia, o riacho Maceió ${ }^{4}$, ainda hoje é elemento físico referencial da cidade.

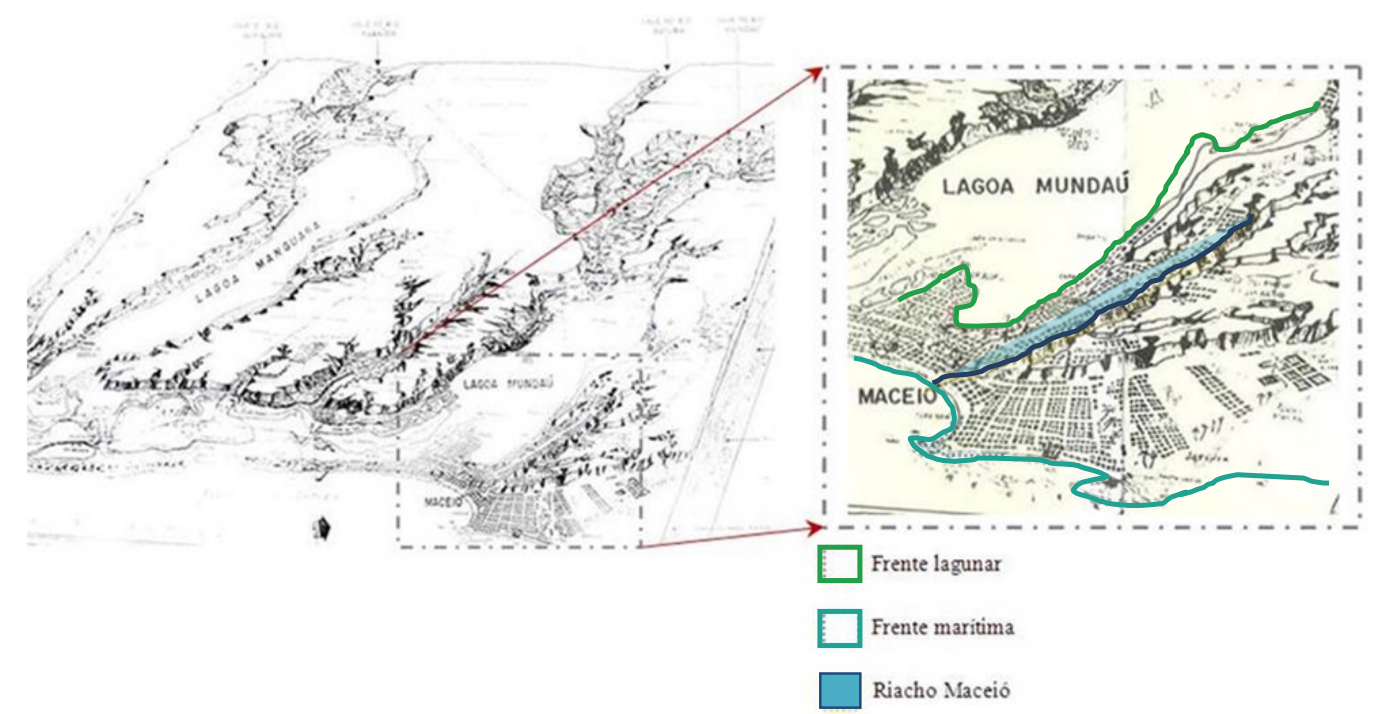

Figura 1 - Localização de Maceió em complexo de águas que a limita. Com detalhe para as frentes marítima e fluvial, e localização do riacho Maceió.

Fonte: LIMA, 2010, p. 58-60. Adaptado, 2014

Maceió, em virtude da presença de extensas áreas úmidas, consolidava-se como uma área desvalorizada. Assim, desde a transferência da capital do Estado para esta cidade em 1839, uma série de intervenções urbanas com finalidades higienistas e de embelezamento foram modificando a natureza local, de forma que o terreno pantanoso composto por rios e alagadiços passou por aterros e drenagens alterando o sítio geográfico. Pedrosa (1998) afirma que:

No início do século, os médicos consideravam o litoral uma região doentia e lá estava Jaraguá 5 com suas febres palustres, intermitentes e biliares, erisipelas, defluxos, coqueluches, e ainda tuberculose, varíola e beribéri. Tudo seria conseqüência dos pântanos que marcavam a paisagem, tanto os

\footnotetext{
${ }^{3} \mathrm{~A}$ cidade de Maceió, nome com origem indígena (tupi), deve sua nomenclatura às águas. Originou-se a partir do riacho Massayó ou Maçai-ok, que significa "aquilo que tapa o alagadiço", no qual posteriormente pode ter dado nome a um antigo engenho de açúcar localizado onde hoje é o Centro da cidade, um dos primeiros focos populacionais (DUARTE, 1982). Esse riacho apresenta-se como objeto de estudo desse artigo.

4 Também conhecido como riacho Reginaldo, em referência ao nome de um antigo dono das terras do Poço que o envolviam, e ainda como Salgadinho, já mais próximo a sua foz.

${ }^{5}$ Bairro onde se localiza o porto marítimo da cidade de Maceió.
} 
naturais como os formados pelo escoamento das águas fluviais e esgotos, das casas sem fossa que lançavam fezes e urina nas sarjetas a céu aberto, situação agravada pelas enxurradas de inverno, inundando ruas, quintais e pátios, (...). (PEDROSA, 1998, p.69)

As alterações urbanas também estavam relacionadas com o interesse em uma maior comunicação, que até então se dava através de pontes entre as duas regiões que compunham a cidade naquele momento: Jaraguá, que continha o porto marítimo, e Maceió (centro urbano), constituindo o eixo comercial (Imagem 2).

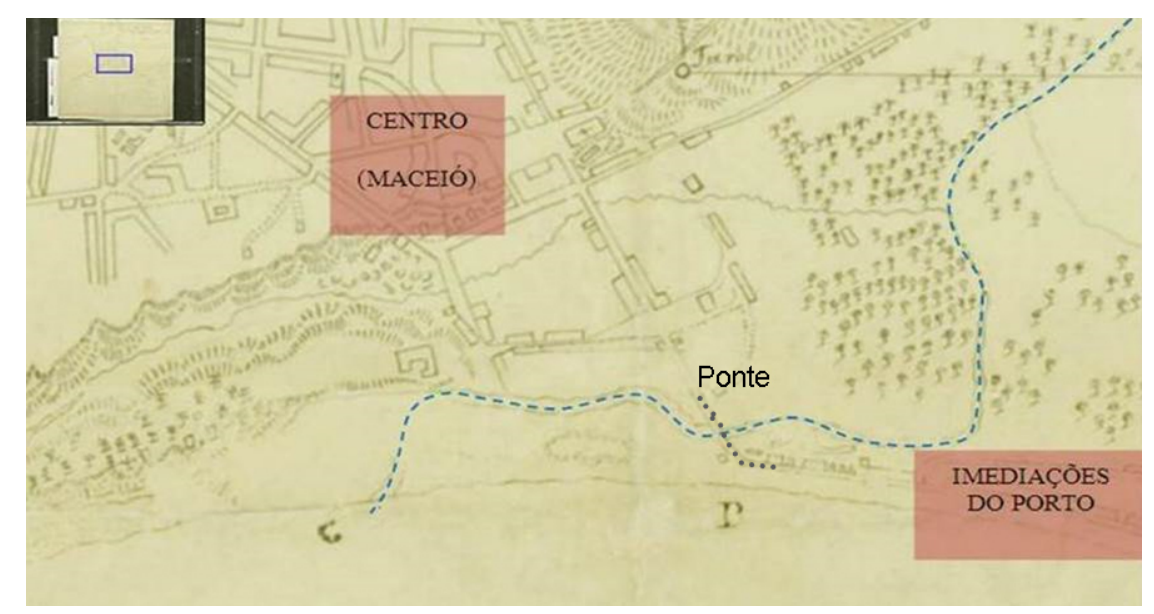

Figura 2 - Detalhe de uma planta da cidade em 1865: o riacho (em destaque) ainda com suas margens vegetadas e apresentando curso original, paralelo à costa marítima.

Fonte: Organizada pelo engo civil Carlos Boltenstern em 1865. Disponível em:

<http://sistemas.ahex.ensino.eb.br/sistarq/imagem.php?codigounion=mapo1486>. Acesso em: $17 \mathrm{fev}$ 2014.

Essas pontes construídas de madeira, muitas vezes de maneira improvisada permitindo apenas a circulação de pedestres, ao longo dos anos frequentemente requeriam alguma intervenção. Em 1857 a principal ponte que fazia a comunicação entre o Centro e o Porto foi considerada em estado de ruínas (CAVALCANTI, 1998).

Nos anos 1869, o então Presidente da Província José Bento da Cunha Figueiredo Junior, solicitou a reconstrução da ponte com estrutura de ferro, para que se pudesse transitar além de pedestres, veículos e posteriormente bondes, sendo a mesma inaugurada em 1871, sob o nome de Ponte dos Fonseca ${ }^{6}$ (Imagem 3). Sobre o mesmo riacho foram construídas mais duas pontes, uma ainda de madeira e outra de madeira e alvenaria, a fim de ampliar as possibilidades de conexão com o porto.

\footnotetext{
${ }^{6} \mathrm{O}$ nome foi uma homenagem a família de Marechal Deodoro da Fonseca, que tinha ido a guerra do Paraguai com mais 5 irmãos, em que 3 deles morreram.
} 


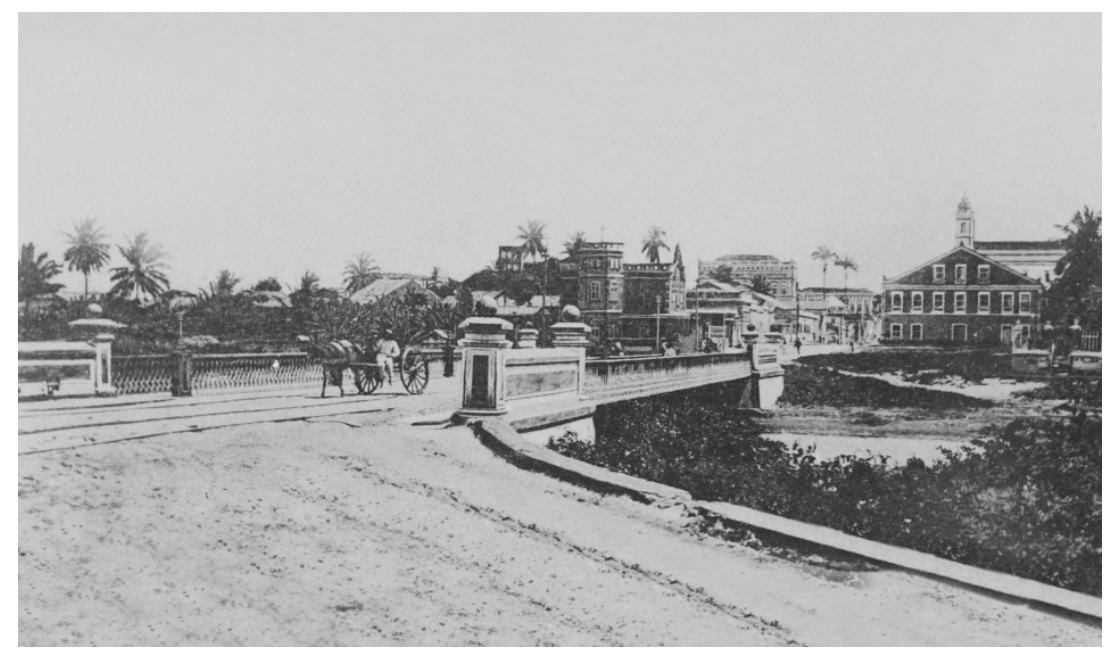

Figura 3 - Ponte dos Fonseca sobre o riacho Maceió no final do século XIX.

Fonte: Imagem de domínio público, s/d. Acesso em 2014.

Com a instituição do regime republicano a partir de 1890, sucede em Maceió um grande surto progressista, resultado da ampliação das finanças públicas. Enquanto abriam-se e alargavam-se ruas, executavam novos aterros, construíam-se praças, a população crescia, e em 1894 a cidade já se dividia em 3 bairros distintos: Maceió (centro comercial), Jaraguá e Levada ou Ponta Grossa. Junto ao riacho Maceió, no início do séc. XX já é possível perceber uma ocupação de forma aparentemente não planejada (Imagem 4).

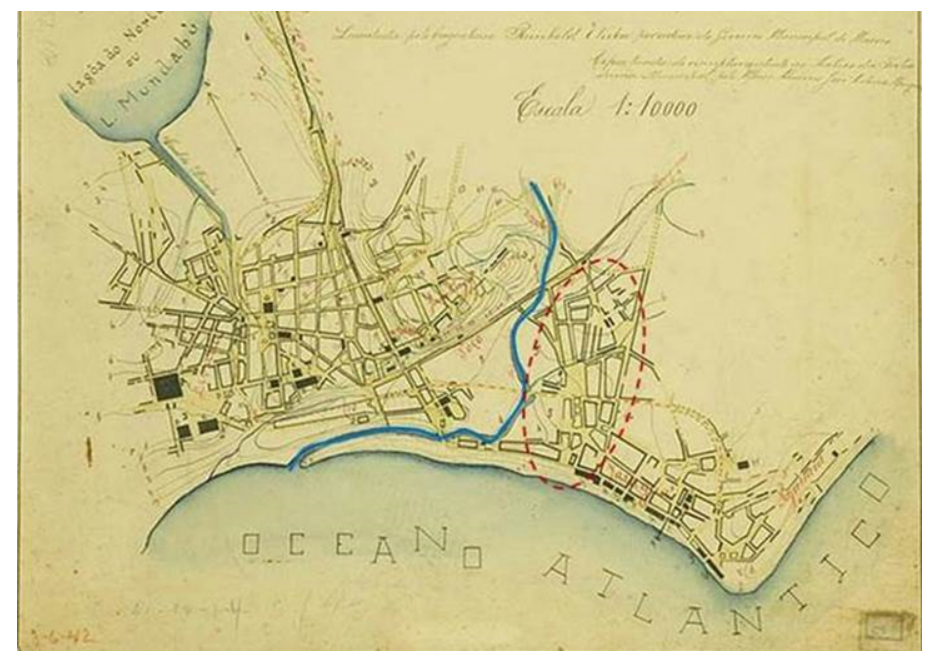

Figura 4 - Planta da cidade em 1902: ocupação ao longo do riacho Maceió com traçado irregular (destacado em vermelho).

Fonte: Planta levantada pelo Engo Reinhold Cvickse em 1902. Disponível em: <http://sistemas.ahex.ensino.eb.br/sistarq/imagem.php?codigounion=mapo1503> Acesso em 17 fev 2014. Adaptado, 2014. 
Observa-se então, que o riacho aos poucos é inserido no contexto urbano que se consolidava. Porém, tendo suas margens ocupadas no baixo curso, e em virtude da ausência de saneamento, verificar-se-á que o esgotamento e demais dejetos produzidos nesse entorno passam a ser despejados diretamente no riacho.

Assim, com a finalidade de dar continuidade as ações de embelezamento bastante em voga ainda no início do século $X X$, serão verificadas obras de retificação das margens do riacho Maceió, com uso de talude vegetado no trecho próximo a Ponte dos Fonseca (Imagem 5). Nesta área da cidade estavam havendo grandes investimentos, como na praça vizinha Euclides Malta. Segundo Ferrare (2008) até as décadas de 1910 e de 1920, o eixo que propiciava a união entre o Centro e Jaraguá através da Ponte dos Fonseca tornou-se o eixo de excelência dos passeios dos moradores.

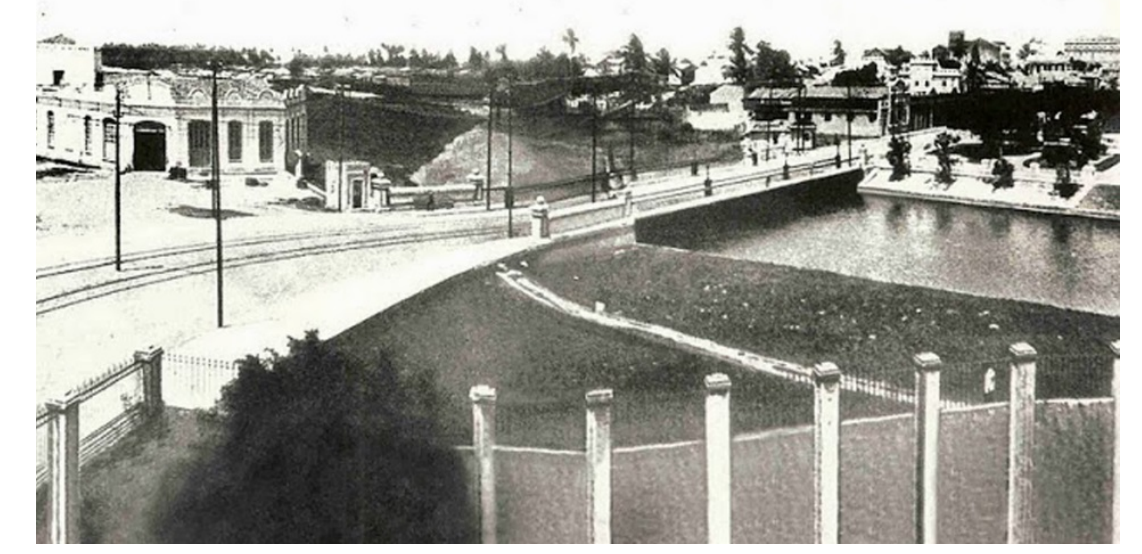

Figura 5 - Ponte dos Fonseca sobre o riacho Maceió no início do século XX. Fonte: Domínio público, s/d. Acesso em 2013.

De tal modo, que essa área tornou-se cartão postal da cidade, veiculado entre 1910 e 1911 (Imagem6). 


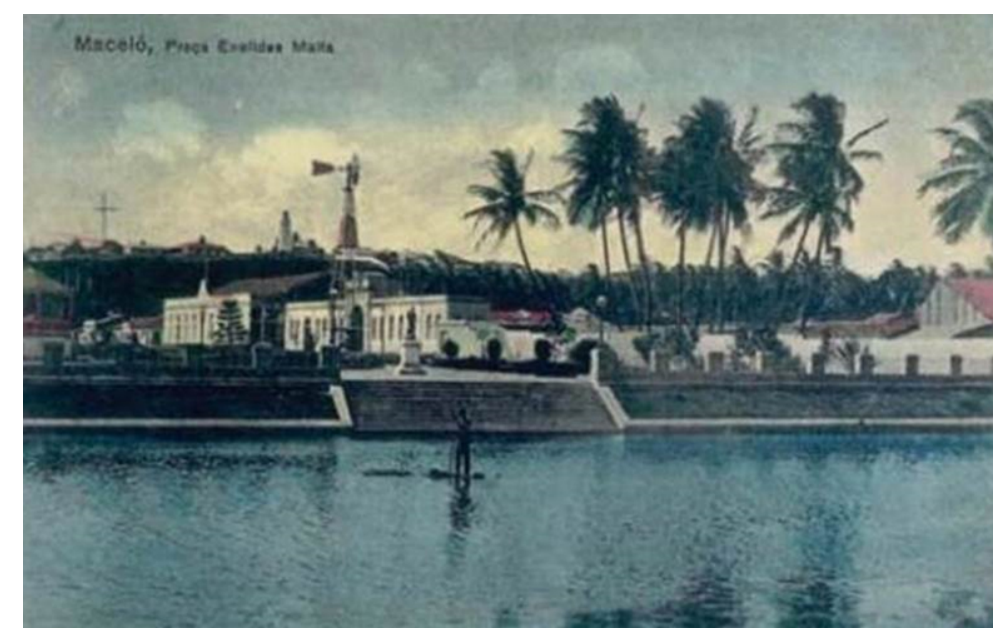

Figura 6 - Cartão postal de 1910-1911: vista da praça Euclides Malta (atual Sinimbú) com riacho Maceió em primeiro plano.

Fonte: CAMPELLO, 2009.

Entretanto, as novas intervenções não puderam evitar as catástrofes resultantes de mais uma enchente do riacho Maceió em abril de 1924. A Ponte dos Fonseca, agora de ferro, construída com o argumento de que ofereceria solidez, segurança, comodidade e elegância, foi destruída deixando novamente incomunicáveis os bairros do Centro e Jaraguá (Imagem 7).

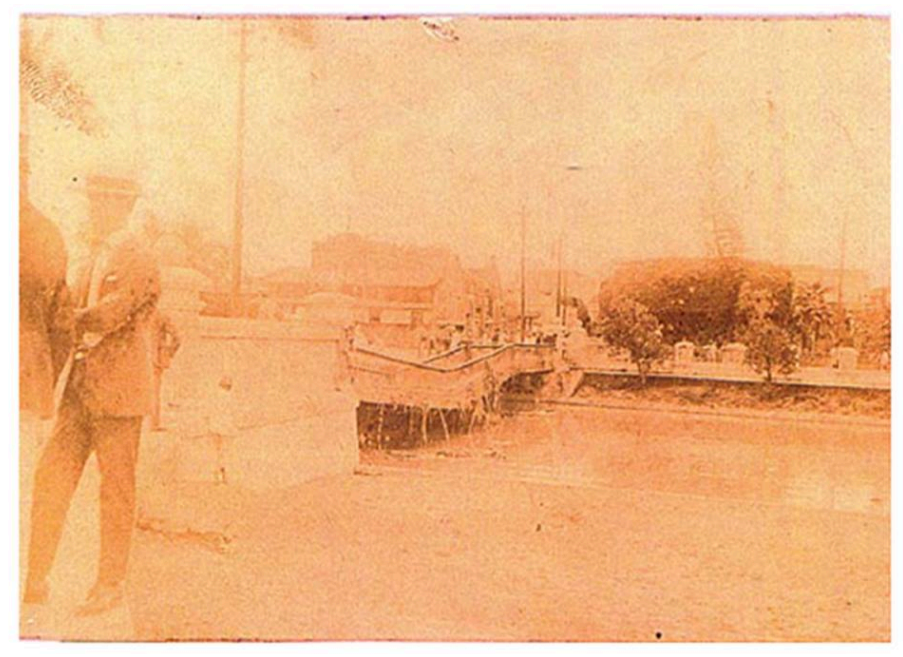

Figura 7 - Ponte dos Fonseca depois da enxurrada de 1924.

Fonte: CAMPELLO, 2009.

A ponte foi mais uma refeita, dessa em vez, em alvenaria e abaulada, pois estudos apontavam que o fato da ponte de ferro ser reta, teria influenciado na sua 
destruição. Nos anos seguintes continuaram as obras de embelezamento da cidade, sendo executada a orla na Avenida da Paz e a Praça Napoleão Goulart (Imagem8).

Entretanto, acrescenta Ferrare (2008:7) que apesar de todo esse ambiente construído que é tão representativo do contexto sócio-político-econômico do Período Republicano, mudanças abruptas se seguem neste cenário quando os "arroubos do progresso exigiram o aterro do leito do Riacho Salgadinho (Maceió) e o seu desembocar direto na Praia da Avenida, em troca de uma faixa de solo disponível para mais construções".

Com a ampliação do porto em fins da década de 1930, a área demandava por novas possibilidades. O riacho Maceió e seus meandros ainda eram vistos como obstáculos à expansão urbana, uma vez que se pretendia a ampliação/ ocupação da costa.

\section{A retificação do riacho Maceió: compreendendo a grande transformação a partir de jornais de 1947 a 1949}

Verifica-se que ao longo do discurso progressista o riacho Maceió passou por algumas intervenções ora indiretas ora diretas, mas a pressão por aterrar sua foz original e ampliar a área territorial levou a um projeto ousado que acarretou, por sua vez, uma grande transformação física e até de significado do riacho.

A obra realizada pelo Departamento Nacional de Obras do Saneamento DNOS, prolongaria a Avenida Duque de Caxias, resolvendo naquele momento o problema de tráfego entre Jaraguá e Maceió, além do que possibilitaria a ocupação efetiva do antigo leito do riacho e de uma área até então inundável devido à mobilidade da boca do mesmo, resultado de sua foz arenosa (Imagem 8).

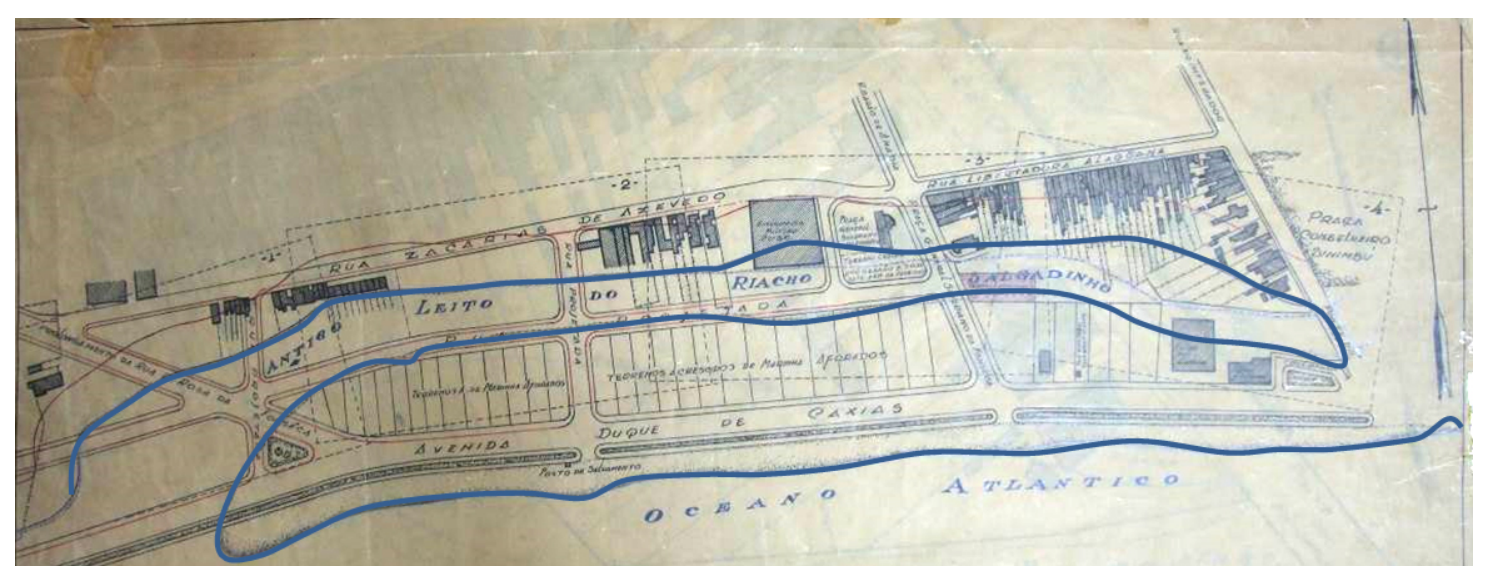

Figura 8 - Mapa de 1955 (da linha do preamar médio de 1831) com a marcação do antigo leito do riacho Maceió e o território anexado.

Fonte: Serviço do Patrimônio da União, 1955. Acesso em 2014. 
Notícias veiculadas no Jornal de Alagoas, a partir de janeiro e 1947, revelavam a preocupação quanto aos danos que uma obra de retificação e mudança de curso do riacho poderia causar à cidade. A população mostrou-se descontente e preocupou-se com os resultados dessa modificação, que afetaria não somente o ciclo do riacho, mas também a segurança das pessoas que habitavam em seu entorno. A partir do ponto de vista geomorfológico ${ }^{7}$, a ocupação ou realização de atividades nas proximidades dos corpos d'água, ou mesmo em suas margens e no seu próprio curso, deveria ser precedida de estudos que revelassem as potencialidades ou riscos para o homem e o meio ambiente. No entanto, apesar da menção a um estudo sobre os impactos que a obra poderia causar ao meio, não foram encontrados registros convincentes sobre o assunto.

No Jornal de Alagoas datado de 16 de Janeiro de 1947, apresenta-se uma primeira crítica encontrada sobre a obra de retificação:

Não é preciso ser "psicólogo experimental", ou engenheiro hidráulico, para prever que o Salgadinho (riacho Maceió) não concordará com a opinião dos que o removeram para a Avenida Duque de Caxias.

Se os engenheiros não tomarem providências preventivas, devagarinho o riacho quebrará a linha reta, à saída, fazendo um caminho para a direita. (JORNAL DE ALAGOAS, 1947)

Contudo em resposta às opiniões contrárias à retificação, na reportagem de título "A obra do Salgadinho, uma vez concluída satisfará o gosto estético da população de Maceió", o engenheiro-chefe do distrito do Nordeste do DNOS, Dr. Prospero Vitalo, em entrevista ao Jornal de Alagoas em 1947 rebateu da seguinte maneira:

Não nos pareceu justas as críticas feitas ao serviço do D.N.O.S. aqui em Maceió. (...) Acontece que, por serem técnicos os que operam no departamento, estudaram e projetaram obra de regularização para o canal do Reginaldo que, estamos certos, uma vez concluída, satisfará o apurado gosto estético da população de Maceió ao mesmo tempo que, hidraulicamente, atenderá as exigências de descarga da bacia hidrográfica. (JORNAL DE ALAGOAS, 1947).

\footnotetext{
${ }^{7} \mathrm{~A}$ geomorfologia urbana deve ser vista como parte da dinâmica de mudanças do sistema urbano e oferece a compreensão dos processos ambientais, bem como das metamorfoses ocorridas na paisagem, resultantes da ação antrópica no espaço urbano (GUERRA, 2011).
} 
Essa publicação pode mesmo ter provocado, a princípio, um movimento positivo na sociedade acerca da obra de retificação do riacho, inclusive pela divulgação de uma perspectiva gráfica apresentando seu produto final (Imagem 9). Não obstante, esse movimento não permaneceu muito tempo, visto que "a cultura alagoana incorpora em seu esquema de valores as contradições geradas em nível social, porque não existe cultura separada da sociedade" (LINDOSO, 2005, p. 64). Os valores da cultura definem as condições de estabilidade das relações sociais e traçam o perfil de identidade das camadas populacionais, configurando suas formas históricas.

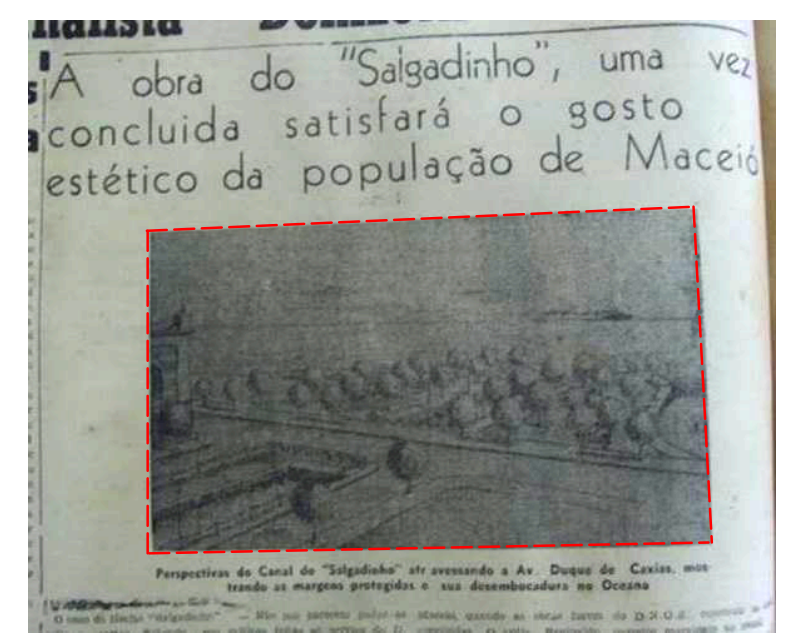

Figura 9 - Notícia que revela o discurso sobre obra no riacho Maceió: destaque para uma representação gráfica da proposta.

Fonte: Jornal de Alagoas, 22 de Maio de 1947. Disponível em Arquivo Público de Alagoas, 2014.

Após o início das obras, o riacho Maceió sobrepôs-se à ação do homem. Depois da declaração da DNOS sobre a importância da obra de retificação, demonstrando suas vantagens para a vida da população, não demorou veio a notícia publicada em 01 de Outubro de 1947 em que o riacho Maceió "derrubou um dos paredões de represamento no lado oposto ao oitão do 'Hotel Atlântico'" (JORNAL DE ALAGOAS, 1947), demonstrando "descontentamento" com o novo curso que Ihe foi imposto, conforme previsto em críticas publicadas no jornal e apresentadas anteriormente (Imagem 10). 


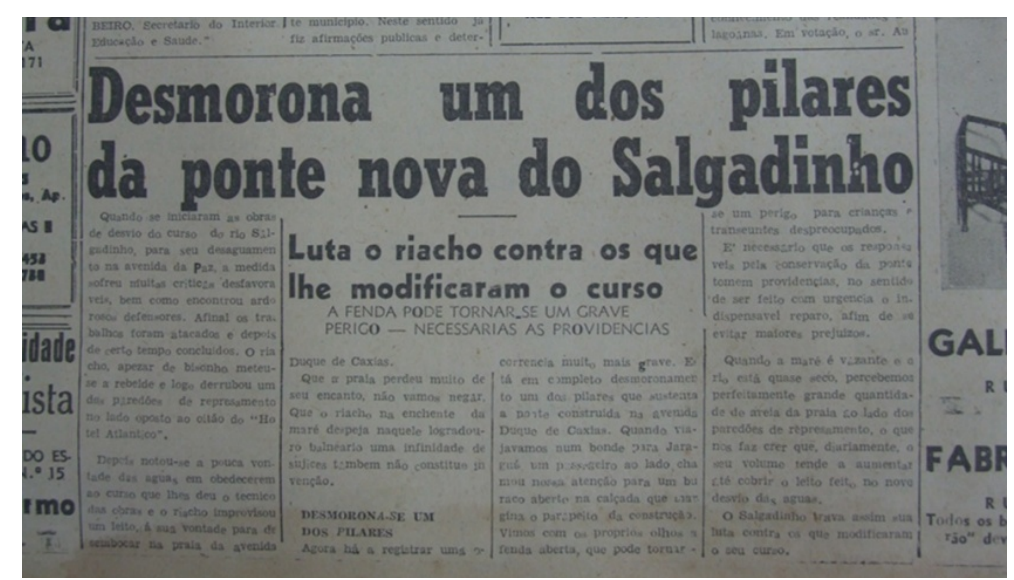

Figura 10 - Notícia sobre desmoronamento de paredão da obra de retificação do riacho Maceió. Fonte: Jornal de Alagoas, 01 de Outubro de 1947. Disponível em Arquivo Público de Alagoas, 2013.

Em 25 de Maio de 1948 uma publicação recorda o quanto a sociedade punia a obra de retificação, que já apresentava aspectos negativos para a cidade, principalmente quando se tratava de sua estética. "Quando os engenheiros do DNOS traçaram o plano de retificação do Salgadinho, a imprensa de nosso estado abriu as baterias entre aquilo que a população de Maceió considerou, desde logo, um atentado a estética da cidade" (JORNAL DE ALAGOAS, 1948).

No entanto, as obras continuaram, enquanto iam sendo executadas, as notícias abordavam o desenvolvimento e progresso alcançado. Como pode ser visualizado na reportagem de 31 de maio de 1948 no Jornal de Alagoas, em que se ressalta a importância do prefeito nesse processo e apresentava-se o trecho ampliado da Av. Duque de Caxias, a partir do aterro de parte do leito do riacho (Imagem 11).

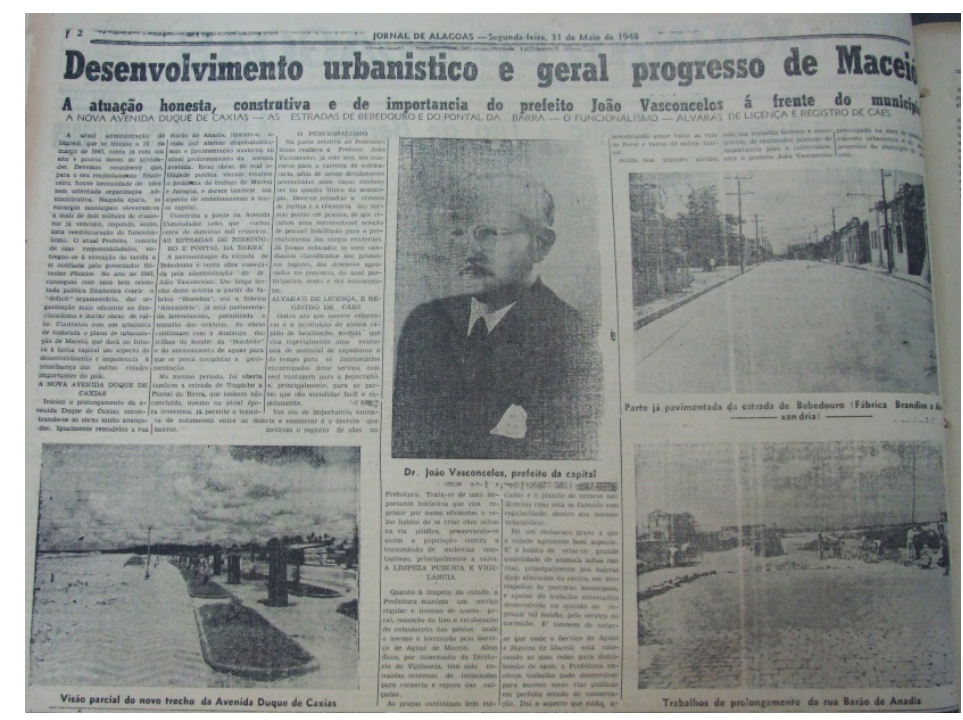

Figura 11 -Notícia ressaltando o desenvolvimento e progresso de Maceió a partir da alteração do curso do riacho Maceió. 
Fonte: Jornal de Alagoas, 31 de maio de 1948. Disponível em Arquivo Público de Alagoas, 2013.

A fim de melhor ilustrar o que significou essa grande obra de intervenção no curso do riacho Maceió, recorreu-se a sobreposição da planta da cidade de 1931, ou seja, antes de qualquer alteração no leito do riacho sobre a imagem área da cidade de Maceió de 2013 (Imagem 12).

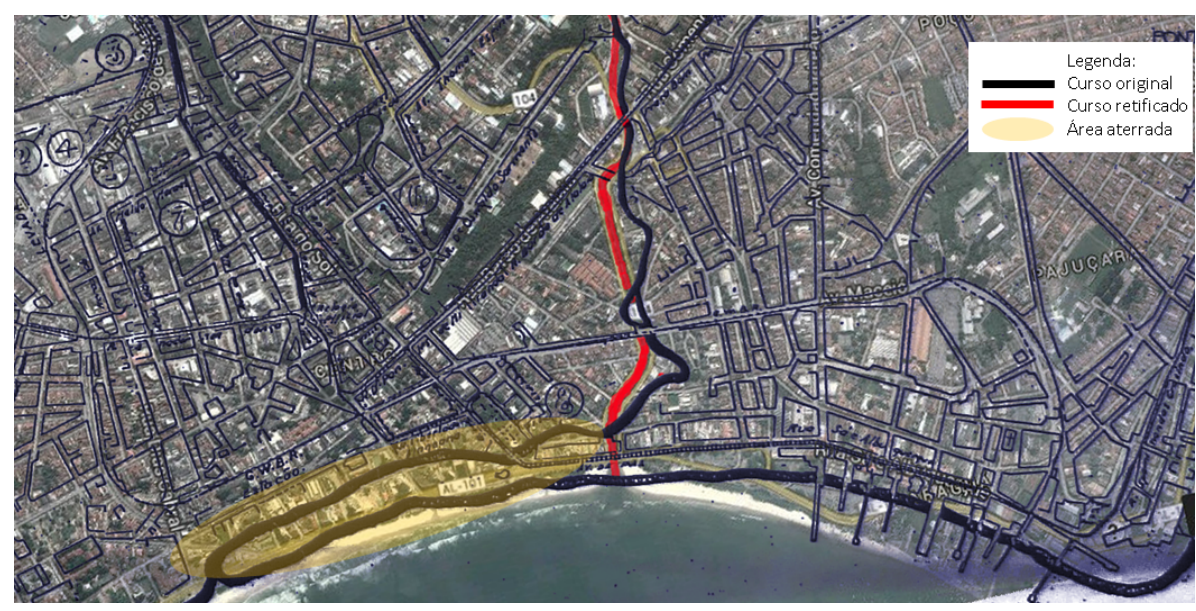

Figura 12 - Superposição da planta da cidade em 1931 sobre imagem aérea atual identificando os cursos do riacho antes e após a intervenção, assim como a área incorporada.

Fonte: Secretaria Municipal de Planejamento (SEMPLA) e Google Maps, 2014. Adaptado, 2014.

Como se pode observar, a intervenção acarretou o aterro de boa parte de seu curso final com consequente expansão da planície litorânea no sentido sul e promoveu a retificação dos meandros do riacho Maceió (Imagem 13). 


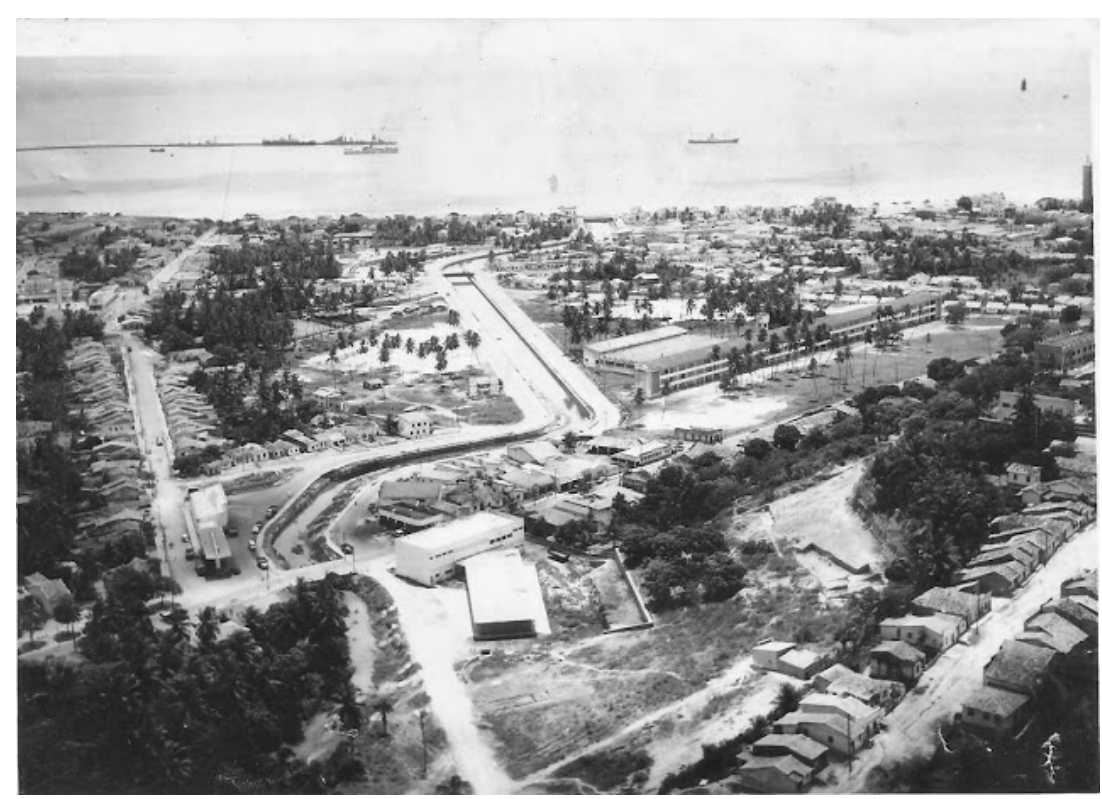

Figura 13 - Riacho Maceió após a retificação e alteração do curso com sua nova foz na década de 1960. Fonte: Domínio Público, s/d.

Embora as intenções estivessem relacionadas à expansão da malha urbana, também se acreditava que essas ações diminuiriam as enchentes, uma vez que a retificação encurtaria a distância do riacho ao mar, aumentando o declive que facilitaria na sua descarga. Revelando-se em seguida contrário, uma vez que o Maceió é um riacho de enxurrada, por ocasião de chuvas mais intensas e fortes, sem seus meandros que permitem a diminuição de sua velocidade, as inundações em períodos de intensa chuva continuaram a acontecer.

Como exemplo, a nova enchente ocorrida em 1949, possivelmente mais violenta que as anteriores à obra, o que contrariou as intenções previstas em projeto menos de um ano após a conclusão.

As cheias atingem a sociedade de forma drástica, diminuindo a qualidade de vida do ser humano, e até mesmo levando a morte. Isso ocorreu como consequência dessa devastação causada pelo próprio homem. Segundo Brandão (2001), "a natureza, atua sobre o Homem e, inversamente, o Homem atua sobre a natureza. Resulta, daí, uma ação recíproca" (BRANDÃO, 2001, p. 10).A notícia de 21 de Maio de 1949 do Jornal de Alagoas revela o caos que era vivenciado pela sociedade naquela época (Imagens 14 e 15). 

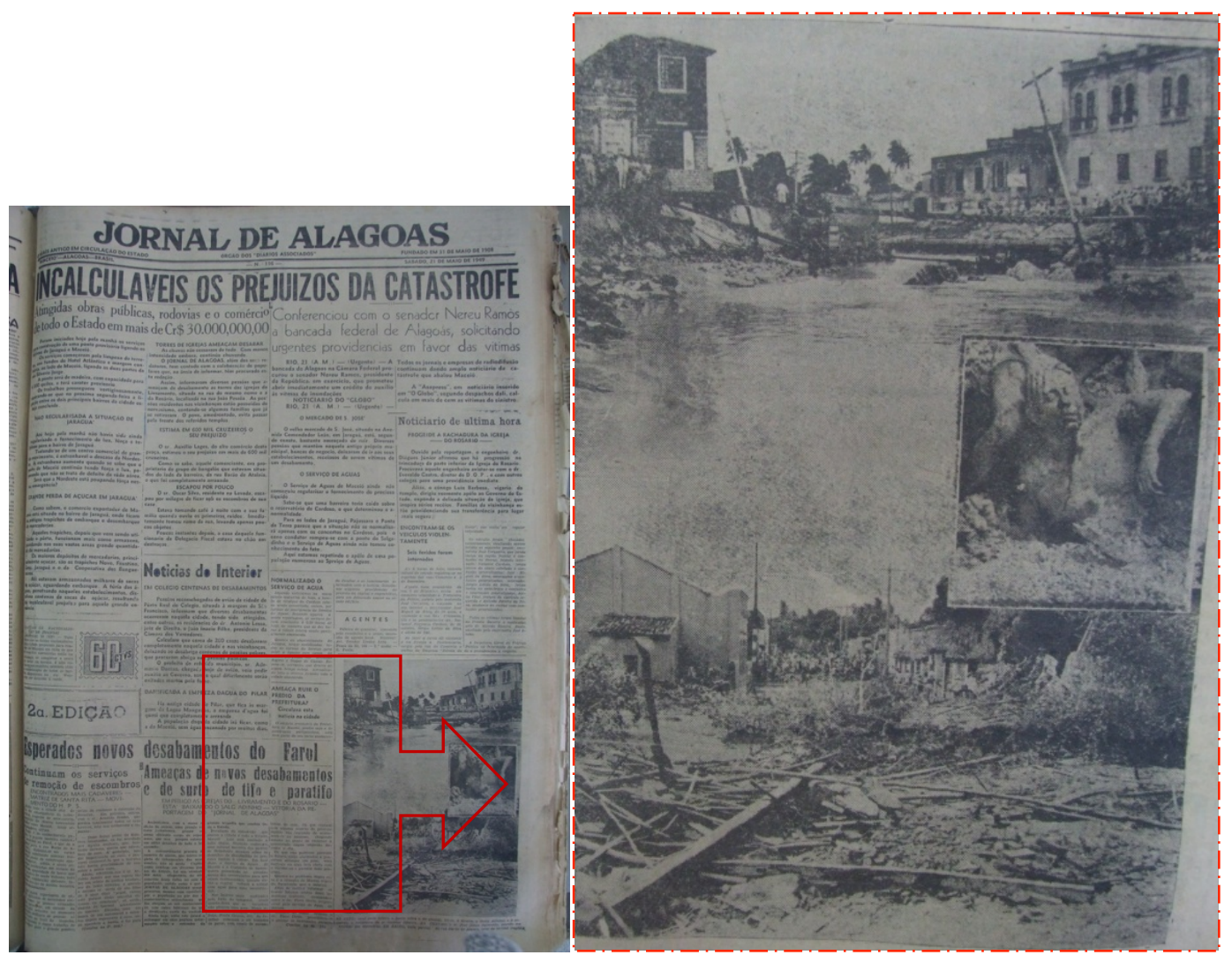

Figura 14 - Notícia sobre os prejuízos das enchentes ocorridas em 1949.

Fonte: Jornal de Alagoas, 21 de Maio de 1949. Disponível em Arquivo Público de Alagoas, 2013.

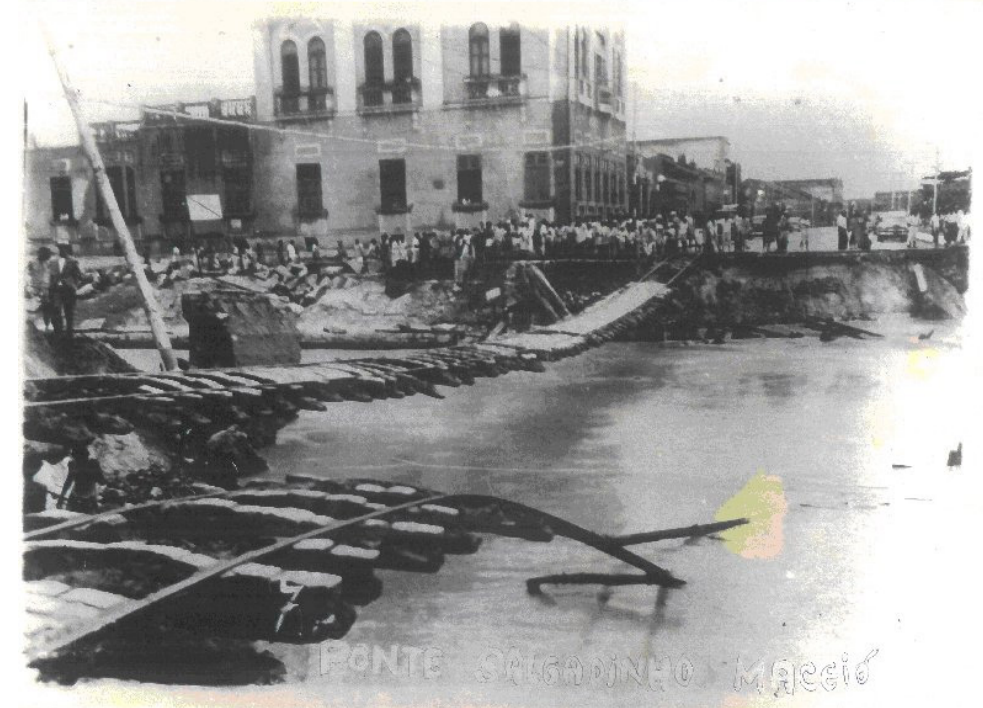

Figura 15 - Consequências para a ponte sobre a nova foz do riacho Maceió após a enchente de 1949. Fonte: Domínio Público, 1949. Acesso em 2014.

A ponte foi reconstruída e a nova foz mantida. As promessas de ganhos para a cidade a partir da intervenção, em termos de evitar enchentes e agradar àqueles que 
zelam pelas belezas naturais da cidade, não se confirmaram. Atualmente o riacho encontra-se poluído e com suas margens pavimentadas (Imagem 16), e apesar de ainda ter alguma vegetação, perdeu sua mata ciliar considerada importante para o funcionamento hidrológico das bacias e o equilíbrio ambiental.

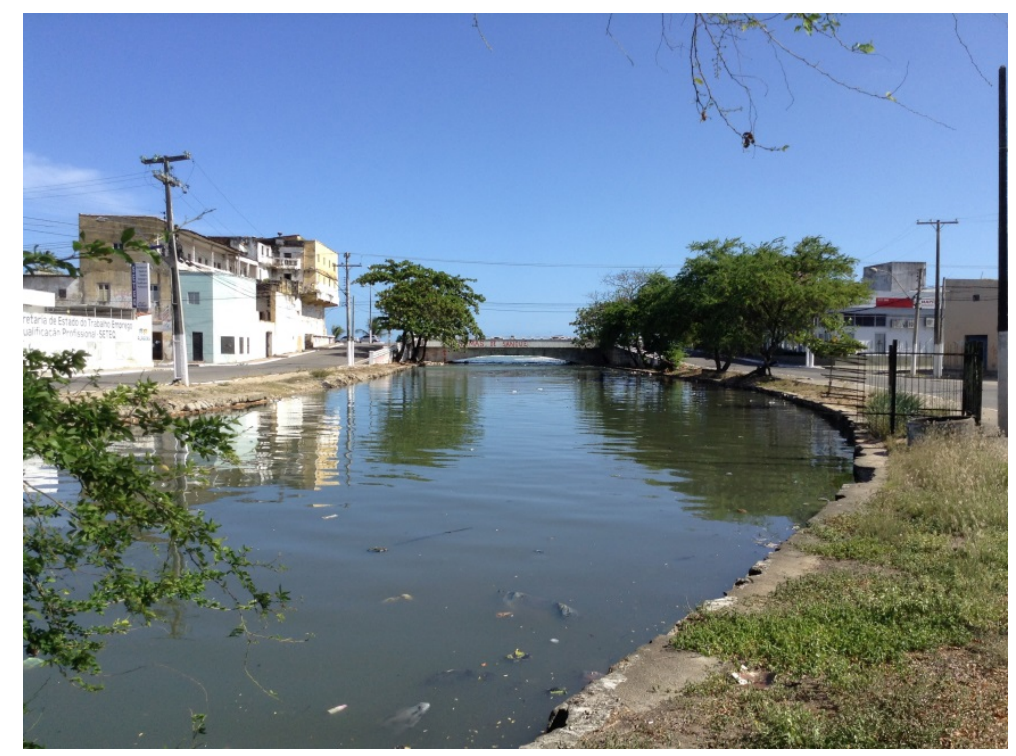

Figura 16 - Imagem atual do riacho Maceió, retificado e poluído.

Fonte: Acervo pessoal, 2014.

\section{Considerações}

A partir do levantamento em busca de informações históricas nas reportagens do Jornal de Alagoas entre 1947 a 1949, foi possível compreender a evolução dos acontecimentos históricos do riacho Maceió e sua relação com o meio urbano, de acordo com o movimento da sociedade. Com a retificação, o riacho Maceió, antes considerado um cartão postal da cidade, perdeu sua identidade. Atualmente apresenta sérios problemas decorrentes do despejo de esgotos sem tratamento, agravado pela ocupação ao longo de toda a sua bacia, em torno da qual a cidade se desenvolveu rumo a uma área de planalto. As matas antes existentes em suas margens foram substituídas por casebres, o que contribuiu para a escassez das suas águas nos dias atuais. A sociedade não o reconhece mais como riacho, e pouco se sabe ou se fala sobre o que foi um dia o riacho Maceió e sua importância para a história da cidade e de sua ocupação.

\section{Referências bibliográficas}

ANTUNES, Lúcia M. S (org.) (2006). Rios e Paisagens Urbanas em Cidades

Brasileiras. Rio de Janeiro: Editora Viana \& Mosley: Editora PROURB. 
BRANDÃO, Octávio (2001). Canais e Lagoas. 3a ed. Maceió: EdUFAL. Vol. 1. CAMPELLO, Maria de Fátima de Mello Barreto (2009). A construção coletiva da imagem de Maceió: cartões-postais 1903/1934. Recife: Universidade Federal de Pernambuco, Programa de Pós- Graduação em Desenvolvimento Urbano (Tese de doutorado).

CAVALCANTI, Veronica Robalinho (1998). La production de I'espace à Maceió (1800-1930). Tese de doutorado em Desenvolvimento econômico e social. Université de Paris I, Panthéon-Sorbonne.

CHAUÍ, Marilena (2006). Simulacro e Poder: uma análise da mídia. São Paulo: Editora Fundação Perseu Abramo.

DUARTE, Abelardo (1982). As Características histórico-geográficas da cidade de Maceió. In: Revista do Instituto Histórico e Geográfico de Alagoas, Maceió: Imprensa Oficial. pp. 13-30.

FERRARE, Josemary. Permanências modernistas na Praça Sinimbú - Maceió: em análise e proposta de preservação. In: Anais $2^{\circ}$ Seminário DOCOMOMO N-NE, Faculdade de Arquitetura da Universidade Federal da Bahia, Salavador, 2008.

GUERRA, Antonio José Texeira (org.) (2011). Geomorfologia Urbana. Rio de Janeiro: Bertrand Brasil.

LINDOSO, Dirceu (2005). Interpretação da Província: estudo da cultura alagoana. $2^{a}$ Ed. Maceió: EdUfal.

MARROQUIM, Adalberto (1922). Terra das Alagoas. Roma: Editori Maglione \& Strini. pp.81-133.

PEDROSA, José Fernando de Maya (1998). Histórias do Velho Jaraguá. Maceió: Editora Talentos.

SANTOS, José Luiz dos (2006). O que é Cultura. São Paulo: Editora Brasiliense.

SANTOS, Milton (2006). A Natureza do Espaço: técnica e tempo, razão e emoção. São Paulo: EdUsp.

SANTOS, Milton (2012). Metamorfoses do Espaço Habitado: fundamentos teóricos e metodológicos da geografia. São Paulo: Edusp. 